\title{
The Integrated Approach for Introducing Innovation in Construction Industry
}

\author{
Nataša Šuman \\ University of Maribor, Faculty \\ of Civil Engineering, \\ Maribor, Slovenia \\ natasa.suman@um.si
}

\author{
Martina Semič El-Masri \\ Geomass s.p.; Maribor, Slovenia \\ tina.semic@gmail.com
}

DOI 10.5592/otmcj.2013.2.2

Research paper

\section{Keywords}

Innovation, Construction Industry, Construction Company, Participants, Partnership Approach, Supply Chain Management
NOWADAYS, INNOVATIONS IN CONSTRUCTION COMPANIES INCREASE WORK PRODUCTIVITY, HENCE, THE EFFECTIVENESS OF COMPANY ECONOMY IS IMPROVED. Basically, innovation is risky and the chance of success seems small, which usually discourages the construction companies to go for it. However, only the companies which will be dynamic and open enough, and thereby capable of responding to the challenges of globalisation, are going to survive. This article offers an overview of the state of the innovation activity in Slovenia, and discusses the impact and problems of introduction of innovation in the construction industry. The integrated approach for the implementation of innovations in construction industry is given within the basic factors for a successful implementation and relevant elements resulting from the internal and external environment. Regarding to the elements of research, possible forms of innovation, benefits of innovation and the inhibitors that limited its assertion are conducted. Further discussed are the factors and the participants which majorly influence the occurrence of innovation in construction industry. Among factors, we have considered participants who can aid at implementing innovation. Those are: the investors, the companies which produce construction products, engineers, architects, the providers of the technical support, and the main building contractors. In the last part of the article, a general overview of two non-technological approaches for expanding innovation is given, with the emphasis on partnership and supply chain management. 


\section{INTRODUCTION}

As a result of the speed with which the global market is moving today, only those companies are going to remain ahead of others which are able to introduce novelties and manage risks connected with them (Foust, 2008). According to Slaughter (1998), the environment of the construction industry has been extremely dynamic through the entire history. There are many new clients or investors who have greater and greater demands and expectations for the quality and choice of products or services. Therefore, Slaughter (1998) points out that the basic assignment of each construction company is to meet the needs and wishes of investors and clients, and thereby ensure the possibilities for existence and further growth.

Because of competition in the market, we believe innovation is one of the possibilities to achieve further growth of construction companies. They are not only necessary for an individual construction company to survive, and consequently, of the entire construction industry, but represent a driving force of the entire economy. Considering the competitiveness of construction companies and economy in general, promoting and investing in innovations is of key importance. Blayse and Manley (2004) conclude that innovation was one of the sources of productivity and economy in the past. Nowadays, it is also the source for achieving systemic quality, which includes perfect or adequate quality, choice and unique offer.

Desphande et al. (2000) has carried out numerous studies which confirmed a robust positive connection between innovation and the success of construction companies in different contexts. $\mathrm{He}$ also found out that the number of innovations is positively connected with the success of construction companies. Vazquez et al. (2001) agrees with Desphande et al. (2000) and claims that the "innovation degree is positively connected with the success of construction companies, especially by achieving goals connected to the profit of investments, profit margin, sales figures and the success of new products". Similarly, Jimenez-Jimenez et al. (2008) found out that innovation is positively connected to the success of construction companies.

From things discussed, we can conclude that the innovative construction companies should encourage and invest in innovation, and direct their employees to adopt this thinking, as well. We need to be aware that innovation became the one factor which brings prosperity to a company and that we cannot survive without innovation of the construction company in today's turbulent and ever-changing environment.

Innovativeness does not come on its own, among other, one needs to know the factors which influence innovativeness and determine competitive advantages of construction companies, which have changed drastically in the last decade. Konda (2005) points out that the modern marketing economy is one of important factors of innovation in construction industry. Therefore the modern marketing economy demands a complete system of cooperative laws, guarantees for the intellectual property, a well-developed transport and IT infrastructure and a holistic educational system, which enables the country to keep up with the development and adapt to quickly changing circumstances.

Blayse and Manley (2004) define the participants in the of construction processes which can help at implementing innovation. These participants are the contractors, investors, the company which provides the construction products, engineers, architects, providers of the technical support and the building contractors, and others performing tradesman's and installation works (in continuation participants).

The purpose of this article is to present an overview of construction industry and innovation activity in
Slovenian and to discuss the opportunities and problems that occur when introducing innovation in construction industry. The basic aim of the paper is to discuss the factors that affect the successful implementation of innovations and are divided into several internal factorsin a company as well as the elements from the environment that supports innovations. Hence, in article we propose the integrated approach for the implementation of innovation in construction companies within the basic factors for a successful implementation and relevant elements that result from the internal and external environment. As for the first element of innovation, we need to be aware that there are different forms of innovation in the construction industry. While all innovations have benefits on one hand and inhibitors that limit its assertion on the other, we present several of them. Furthermore, the factors and the participants which significantly influence the occurrence of innovation are provided here. In the last part of the article, a nature and importance of introducing two non-technological approaches for expending innovations in Slovenian construction industry is presented. Those are partnership and supply chain management and represent supporting approaches for close and long-term strategic relationships. They are a powerful tool for reducing risk and collecting the necessary funds for innovation.

\section{An overview of the construction industry and innovation activity in Slovenia}

\section{Circumstances in the Slovenian construction industry \\ from 2000 to 2012}

According to the statistic data, the value of construction works performed in 2011, compared to 2008, when the construction activity was at its top, was lower for more than 50\% (SORS, 2012). The value trend of performed 


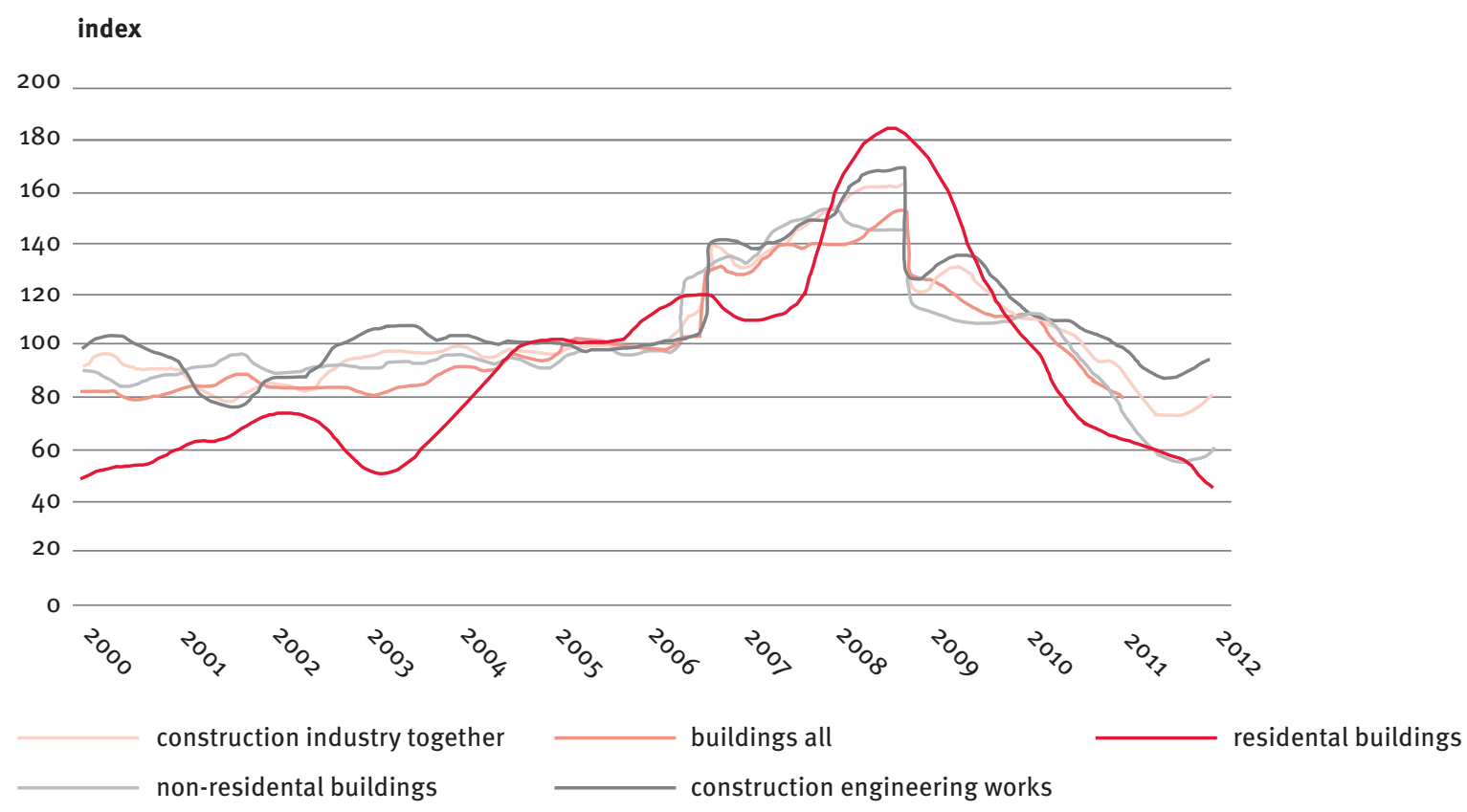

Figure 1. Chart of the Value Trend of the Performed Construction Works in Slovenia, 2002-2012 (Source: SORS, 2012)

construction works, as presented in Figure 1, shows that from the beginning of 2000 on,the construction activity was rising evenly until 2006, with the exception of construction of residential buildings. Afterwards, there was a construction boom. In 2008, the construction industry peaked, and the main reason for its ascent was accelerated construction of residential buildings and engineering works (SORS, 2012). Nowadays, the value of construction works still does not reach the state before the boom. At the moment, the trend is on a similar level as in the beginning of 2000 .

An overview of the innovation activity in Slovenia from 2008 to 2010

According to the statistic data, less than $50 \%$ of all companies implemented the innovation activity, more precisely technical and/or non-technical innovations, in Slovenia between 2008 and 2010. Among companies in Slovenia, there were $49,4 \%$ of such which were innovation active from 2008 to 2010. What is more, among them are those that implemented technical and nontechnical innovations simultaneously were the most numerous $(24,5 \%$ of all companies) (SORS, 2012).

In Table 1 the share of innovation active companies from 2008 to 2010 are presented. There were $54,4 \%$ of the innovation active companies among the companies dealing with processing activities, while there were only 44,7 $\%$ of the innovation active companies among the selected service activities. The construction industry is placed into the second group (SORS, 2012).
According to all innovation active companies, the share of technical innovation according to the specific branch there were more than $43 \%$ of those which are classified into the processing activities of innovation active companies with technological innovations. However, there were more than $26 \%$ among companies which are classified into service activities among others also the construction sector (SORS, 2012).

Among all innovation active companies with technical innovations, not considering their activity, there were

\begin{tabular}{|c|c|c|c|c|}
\hline $\begin{array}{l}\text { Companies } \\
\text { according to } \\
\text { activity }\end{array}$ & $\begin{array}{l}\text { Number of } \\
\text { companies }\end{array}$ & $\begin{array}{c}\text { All innovation } \\
\text { active } \\
\text { companies }\end{array}$ & $\begin{array}{c}\text { Technical } \\
\text { innovation } \\
\text { active } \\
\text { companies }\end{array}$ & $\begin{array}{l}\text { Innovation } \\
\text { of products or } \\
\text { procedures }\end{array}$ \\
\hline $\begin{array}{l}\text { Processing } \\
\text { activities }\end{array}$ & 2.015 & 54,4 & 43,1 & \\
\hline $\begin{array}{l}\text { Service } \\
\text { activities } \\
\text { (also } \\
\text { construction } \\
\text { industry) }\end{array}$ & 1.965 & 44,7 & 26,6 & 48,9 \\
\hline
\end{tabular}

Table 1. The Share of the Innovation Active Companies According to Specific Branch of Activities, Slovenia, 2008-2010, in \% (Source: SORS, 2012) 
most companies, a little less than $49 \%$, which have implemented innovation of products, as well as innovation of procedure (SORS, 2012). $25,5 \%$ of them launched a new and really improved product or a service, and $23,5 \%$ were such which implemented innovation of procedure (new and really improved production procedure, different way of distributing or support action for a product or a service).

From an overview of innovation activity in Slovenia we can conclude that the share of innovation active companies is extremely small, fragmentarily or badly connected, and focused mainly on the transfer of technology. As a result, there is a huge gap between the RD activities and the needs of industry.

Samad (2010)studied and compared the construction sector in Poland, Spain, Greece, Finland and Slovenia. In his brochure Regional Construction Clustering in Action he also discovered that the activity in the area of innovation in the Slovenian construction industry compared to other EU countries shows greater fragmentation or worse connection, and is focused mainly on the transfer of technologies as purchase of new machines.

\section{The opportunities and problems for introduction of innovation in construction industry}

For the construction industry it has become essential to promote and invest in innovation because this factor brings prosperity builders and without it the construction companies in today's turbulent, changing environment, cannot survive.

Samad (2010) established that the transfer of new technologies, which result from cooperation between the Slovenian partners at the European RTR Projects, is not actualised enough to contribute to the growth and modification of the sector. Furthermore, he distinguishes numerous challenges and problems, goals and priorities, which were identified by the members of the Construction Cluster of Slovenia. Hence, the members have enumerated the main challenges and problems of construction companies:

$\checkmark$ fragmentation of the branch in the area of RD and innovation,

$\checkmark$ bad connection between the RD activities in the construction companies and industrial demands,

$\checkmark$ investments in the area of innovation are mainly connected with the purchase of new machines and technologies,

not enough interest of the construction companies for active implementation of innovation,

> the general business environment, regulations and work experience, which are strict and restraining at implementing innovation,

$\checkmark$ a lack of means for investing in RD and

$>$ no support at innovation from the public sector.

One of the important reasons why innovation appears so rarely is also wrong investment policy in public. At the national and international levels changes are needed to promote: planning and execution of activities and services in order to support innovation; integration participants in the RD activities and transferring knowledge and new technologies among the participants. Higher levels of innovation would also requirereconstructing of construction companies by implementing new business and organizational models.

Furthermore, in the period of economic crisis any innovations in construction processes rarely appear. From the aspect of technological innovation, the companies mostly use traditional technological solutions which are already available and do not demand extra investment or additional knowledge and engagement. New technology and materials are used only if they bring direct and immediate savings. In terms of economy this is understandable because unfavourable economy situation and fierce competition bring lower income, and little or no reserve remains after all costs are covered to be spent on extra activities for object completion. For the same reason designers introduce little technological innovations because this means deviation from usual construction and higher project costs which leads to lower chances of winning the project competition. Therefore, less interest in introduction of new technology, materials and knowledge result into deadlock or even decline in the profession. Often the companies agree to take over a business, knowing that they will end up with a loss. In long term this leads to liquidity problems which end with debt settlement or bankruptcy.

Among others, one of the important reasons is tenders which contributed to today's construction situation where the most successful tenderer is chosen on the basis of the lowest price. Each investor should manage the available means with due diligence. Thus, he should get for his inputs a quality and modern structure which will be functional during its lifetime and will require as less maintenance costs as possible.

Furthermore, by introducing the Regulation (EU) Nr. 305/2011 on Construction Products, a new and crucial demand for the sustainable use of natural resources was implemented, where the environmental characteristics of products need to be exhibited. This introduces a chance for the construction companies to react and produce or install products which are more acceptable for the environment. As a result, competitiveness to the construction companies will increase as well.

\section{The integrated approach for introducing innovation in construction industry}

It has been already established that innovations are necessary for the development and preservation of competitiveness. However, the lack of experience and finances are big 


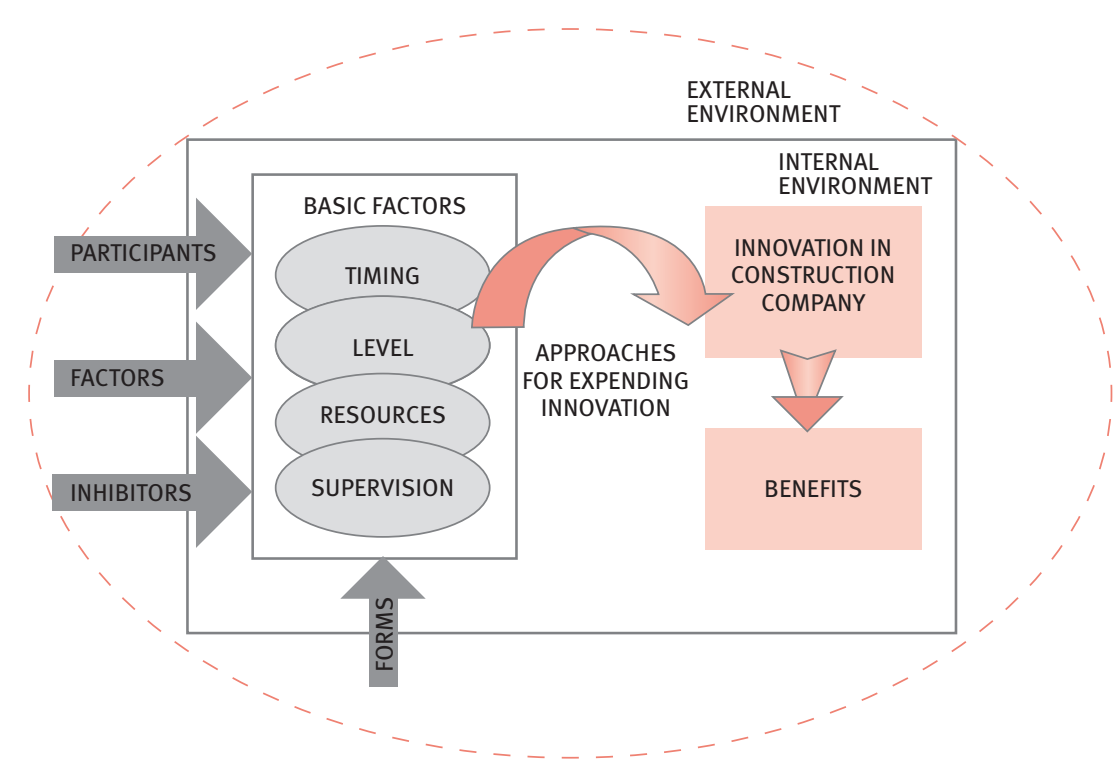

Figure 2. The integrated approach for the implementation of innovation in company

problems in the implementation of innovations. Furthermore, to increase the number of innovations and their successful implementation, two most important aspects of the construction industry need to be considered. These are specific characteristics of the ordered final products, the so called construction works, and a big number of companies or participants who are a part of their realisation.

For a successful implementation of innovations in the company in construction industry, the integrated approach within included basic factors and several relevant elementsis presented in Figure 2. This approach is suitable fora company in construction industry which introduces innovations in its processes. In terms of the company's internal environment, the following basic factors are specifically considered(according to Slaughter, 1998):

the timing, when a construction company decides for innovations; the timing refers to the level of prescribed means for the implementation of innovations, and when a construction company will be able to acknowledge the implication of innovation in public; which can exist only inside the company with specialized professional knowledge;

- the supervision of activities, including the supervision on the organizational level, kinds of supervised activities and certain competences of the supervisors.

Next important elements arising from internal environment of the company are forms of innovation and their benefits. For the purpose of a successful implementation of innovations, the most important element is the application of proper approaches for expanding innovation. Beside the basic factors and elements from internal environment the company needs to consider significant elements of innovation from the external environment. Those elements are participants, the factor of innovation and inhibitors. All internal and external factors and elements are discussed in the next chapters.

The forms of innovation in the construction industry

In innovation theory and practice we could find a numerous forms of innovation. Two most commonly used forms

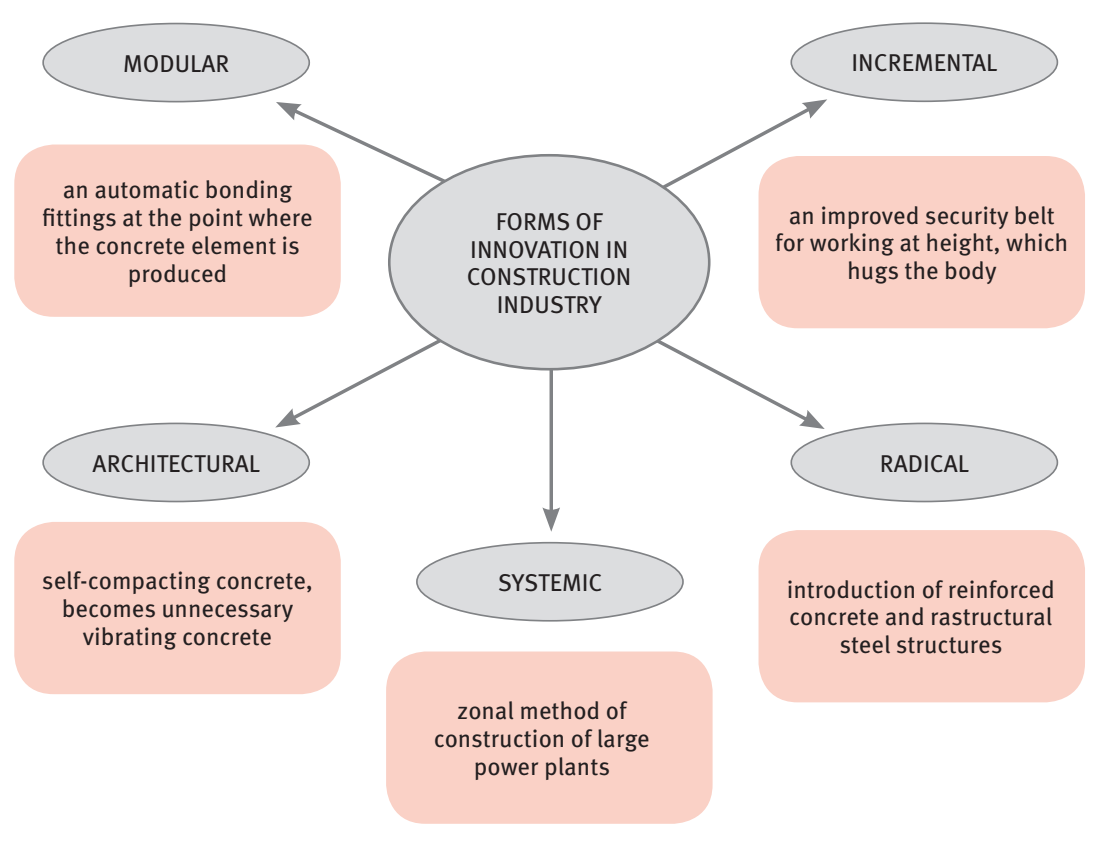

Figure 3. The forms of innovation in construction industry 
are: innovation as a product, which involves the introduction of new or significantly improved product or service (e.g. improved software), and innovation as a process, which involves the implementation of a new or significantly improved production process, distribution method, raw materials etc. of course, both forms of innovation are not mutually exclusive, but mutually connect.

According to Slaughter (1998) and Blayse and Manley (2004), innovation in the construction industry can take different forms. It can be: incremental (small, based on the existing experience and knowledge), radical (a breakthrough in science and technology), modular (the change of scheme inside the object element itself), architectural (changes in connection with other components and systems) and systemic (multiple, integrated innovations) (see Figure 3 ).

Freeman and Perez (1998) describe the forms of innovation in construction industry a little differently than Slaughter and Blayse and Manley. They describes form as: incremental innovation that are constantly occurring as a result of operation of the two principles: learning by doing and learning by using; radical innovation, which include a combination of product, process; and organizational innovation and new technological systems and technological change in the economic paradigm based on a combination of radical and incremental innovations.

Practice has shown that it is necessary to integrate the described forms of innovation in the construction industry and it is important to pay special attention to the proper choice of time which defines resources required for the implementation of innovations. Furthermore, it is necessary to pay attention to the degree to which innovation requires the use of implicit and explicit coordination between project team members (developers, designers, contractors, subcontractors, etc.) Using innovation may require special resources that can be found only in companies with specialized expertise. For this reason, it is necessary to integrate innovation into a specific project focused on the selection of the source and type of professional resources. Attention should be paid to the control activities, including control at the organizational level, as well as type of regulated activities and specific skills of supervisors.

\section{The benefits of innovation in}

\section{construction companies}

When construction companies create an innovation, they offer it in the market, where its participants estimate its usefulness. If they believe that the innovation is useful, they will buy it.The most important benefits of innovation in construction industry are: improving business relationships with investor/ clients and suppliers, opportunity for communication with broader social environment, establishing new business contacts, providing stimulation, creating trust in the company and company's growth.

Usefulness of innovations is not only seen in the above mentioned benefits, but also in profit maximisation of the companies in construction industry. After the implementation of innovations, the innovative companies assure an advantage in the market with their sale and, in this way, create profit maximisation. The competitors will imitate their product later on.Consequently, implemented innovations increase the reputation and recognisability of the companies, and create better general opinion about them among the customers and other public. New business possibilities emerge and they can influence the increase of the market share and result in better reputation of companies, which are now shown in the spotlight of innovative and successful companies, as they do not follow changes in the market, but rather create them.

\section{The participants, factors and inhibitors of innovation}

\section{The participants of innovation}

In the construction industry, generally known participants are: an investor, companies producing the construction products, engineers, architects, providers of the technical support and main building contractors. All of them can contribute to induction of innovation in the construction industry.

The main initiative for innovation in the construction industry is attributed mainly to the clients and investors, who have the leading role in the introduction of innovations. Next are the participants, who are included in the construction processes and in activities that support innovation. If the investor is more demanding and experienced, the likelihood of stimulating innovationat the projects level is greater.

In the construction processes, the subcontractors and suppliers have an important role, too. They form project groups with the construction company and represent the unrealised potential at implementation of innovations.

Nowadays, since the present approaches to the project management did not pay enough attention to the formation of project teams, there is a new trend that builds on developing internal and inter-organizational long-term relationships between the participants and extending the existence of project teams. Despite the fact that the composition of project teams inside the project can be very difficult, its creations demand appropriate time and certain means. However, this can lead to greater stability, mutual trust to the participants and conditions, which enable educating and the development of innovations.

\section{The factors of innovation}

Innovativeness does not come on its own, so we need to know which factors influence innovativeness and determine the competition advantages of 
companies in construction industry. The first factor is cooperation between the university, research institutions and the construction companies that perform construction services, and companies of building material industry. The companies benefit from the cooperation with the universities and research institutes since they are the creator and provider of knowledge.

Moreover, the financial aspect is very important as well. Cooperation with construction companies essentially contributes to the university's ability to develop intellectual property, its protection and application.

The next important factor for innovation is research institutes. Specific research is undertaken there, which, due to a lack of specialised staff or equipment, is not carried out at universities or companies. The reasons for cooperation are similar or maybe even identical as in the previous example. In principle, the institutes have more possibilities to participate in the partnership projects, which receive a government subsidy.

Another important factor of innovating is the government which has to ensure the intellectual infrastructure. The basic task of the government should be to invest in the development of quality universities, create programmes to encourage the development and commercialisation of new technologies, and encourage and connect universities with the local companies.

We should also consider connection of innovations by various factors that influence innovation as: costs related to R \& R activity; the cost of the activities conducted by the other organizations; the cost of purchase of machinery and equipment necessary for the implementation of innovation product, service or process; and the cost of employee training. It is also important the way that companies obtain funds to cover the innovation and development activities, and that they know how to use it. In addition to these factors, we can not forget to mention the factors that determine the need for innovation and setting new benchmarks such as: technological advances, changing needs of clients, competition and changing environment.

\section{The inhibitors of innovation}

The main inhibitor for limited assertion of innovation in the construction industry is usually poor communication between all the participants. Moreover, the enterprise culture and its features are also obstacles for innovation. When innovations are implemented, we need to be aware that the employees also need to be appropriately prepared. They will have to do things differently, which means that it is necessary to abandon old ways and views, and create new directions to work inside the corresponding culture.

According to Jones and Saad (2003), the above mentioned inhibitors of innovation in the construction industry can be improved by ensuring better leadership and development of staff, and by including:

more regular integration of different specialists, subcontractors and suppliers,

$\checkmark$ more effective project management and management of organisations included in the project,

> appropriate and constant learning on individual, project and organisational level,

- new cultures, which support, promote, implement and maintain innovation in the construction industry and

$\checkmark$ more effective external image.

Nevertheless,introducing innovations demands a supporting management which enables internal and external structural changes inside the company. In this case, process management, supporting and promoting innovations represents an encouragement to the individuals and the organization to work together and to establish closer relations. Therefore, it is necessary for the management in the construction companies to support and believe in innovation.

Considering the trends in the construction industry and the implementation of innovations in Slovenia, we encounter several inhibitors and obstacles. The biggest obstacles for the development and launch of innovativeness are the lack of capital and stiffness of the construction industry in which every novelty or innovation must go through a complicated and slow process of introduction for the market. The next obstacle is the short-time viewing of the management of a company. Namely, the most of managers in construction companies usually have a short-time thinking, from a project to a project, and they are focused mainly on the temporary development of the professional competences, and don't have enough knowledge on how to lead innovations and innovativeness.

\section{Expanding innovation in the construction industry}

Expanding innovations is a process through which the manager ensures that individuals and groups accept innovation within their companies, projects and supply chain. However, we need to keep in mind that these processes can take a lot of time mainly due to resistance and fear of changes, adversarial relationships, lack of learning and culture of accusation, which is often present in the construction industry. In expending innovations in the construction industry, technological changes are among the most significant tools in developing competitive advantages and the chief cause of industrial change, where technology cannot be monopolized, since knowledge constantly spreads from construction companies or institutions - to other construction companies or even other countries. It is advisable to start introducing changes in innovation on the project level. This is because 


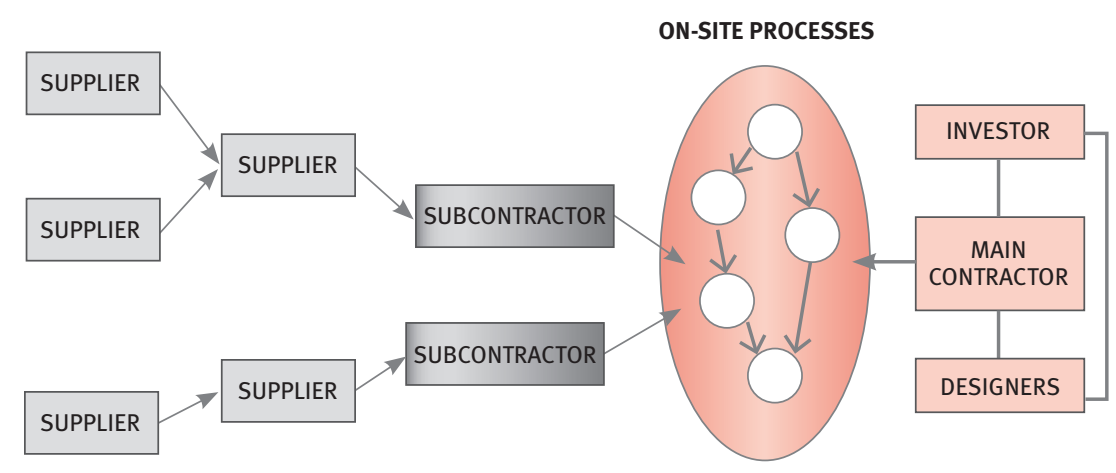

Figure 4. Drivers of supply chain management in construction industry

of the changes arising from complex innovations as well as the nature of the construction process with its projectoriented approach. The reasons are as follows: firstly, a project is the most suitable and convenient context in which one can exert influence on construction companies and help them in their pursuit to adopt innovations; secondly, experience from other sectors indicates that initial challenges associated with the implementation of innovations are most successfully dealt with at work or on the operational level.

The aforementioned manner demonstrates how companies can adopt examples of good practice from projects and apply them in their companies. The next logical step is to expand this knowledge beyond the scope of individual projects. This means that such models, knowledge and examples of best practice, with the aid of new projects, can spread within the construction company to other project teams.

Large and sustainable innovations in the construction processes have been achieved by developing close and long-term strategic relationships based on partnership and the adoption of supply chain management in the construction sector (Jones and Saad, 2003).Next, the nature and importance of introducing two non-technological approaches for expanding innovations in Slovenian construction industry is presented.

\section{The partnership approach}

Partnership is a non-technological innovation and an innovative approach to delivering construction services. Partnership was defined by Myers (2004) as some type of cooperation in which the investors and contractors - in trying to achieve a common goal - tend to become increasingly sincere towards each other.

Partnership approach improved cost and time management reduces the risk of excessive costs and delays, and the open communication and trust between the clients further fosters a climate that encourages innovation. Partnerships enable better planning, safer construction, easier adherence to deadlines and profit maximisation for all parties. The 'partnership approach' is not yet widespread in the construction industry in Slovenia. Adversarial relationships still seem to predominate and are defined in the contracts between the parties. In Slovenia, the traditional goals of construction projects still seem to be in the foreground, i.e. building a facility within the agreed time period, delivering the agreed-upon quality, cost-efficient construction, as well as avoiding close links between the participants in a project.

All advantages of a partnership approach contribute to a greater receptivity of innovation, as well as improved communication and responsiveness whenever problems arise. They also lead to the development of improved inter-personal and inter-organisational trust, higher awareness for developing mutual advantages, and they promote a culture that supports innovation and learning.

The supply chain management approach

Supply chain management is a nontechnological innovation, just like partnering. In the construction industry, supply chain management is related to more advanced forms of partnering. It is being increasingly viewed as an innovation that can solve problems arising in the construction industry. Trontelj (2007) has defined supply chain management as a tool used by the construction companies that enables them to rationalise their production and improve their cost-effectiveness. A supply chain is a network of companies in construction industry that are involved - through high-level and low-level connections - in various processes and activities. The results of those processes and activities are products and services for end users, i.e. investors or users. Figure 4 represents drivers of supply chain management in construction industry, among which are the private and public client and the main contractor. An innovation can occur at every point of the supply chain. Recently, in Slovenia there has been an increase in the awareness of the supply chain management approach utilisation, but it is still too early to assess its broader implementation and its impact. It is, however, clear that the attributes like complexity, process fragmentation, mutual dependence, uncertainties and focus on investors will influence the way in which supply chains and other innovations will be implemented in construction industry practice.

\section{Discussion}

Business operation of construction companies has changed very much in the last decades. From effectiveness, which can be observed in lower costs 
on a production unit, the emphasis was transferred on the quality and on the production flexibility. However, today we are speaking of innovativeness as the main competitive advantage.

Innovations play a dual role in construction companies: uncertainty and a change in their environment on one hand and greater competitive advantages in the construction industry on the other. From a technological point of view, two strategies have opened up a wider discussion about innovating:

the so-called rationalistic approach and

the incremental mode, which is based on the constant adoption of new forms of knowledge and learning.

Each approach has its advantages. The best approach for a particular construction company depends on its current situation. In other words, and given our current situation, each strategy has to be a part of broader process that involves constant learning and thus the accumulation of knowledge and experience, making sure that construction companies can cope with complex situations and change more easily.

The general trend of implementing innovations has not yet wholly caught on in the Slovenian economy and its construction sector. This is probably due to the peculiarities of this sector. The construction industry relies on one-time, unique projects, which often makes the transfer of knowledge between projects more difficult.

Problems arising in the construction phase of projects show that a wider implementation of innovations is needed in construction companies, since the participants on a particular project do not use innovations in this stage. This especially applies to the contractor and the investor, who have the largest influence on the implementation of innovations on a particular construction project. The implementation of innovations in construction companies is thus necessary, not least due to the fact that it can facilitate communication between the participants on the project. This communication process generally leaves a lot to be desired, and this is the main culprit for delays and poor quality. All too rarely do companies assess the progress of a project, which especially applies to delays, and provide solutions to minimize or avoid them. Investors need to be aware of the pitfalls of choosing the supposedly cheapest contractor. It often turns out that such contractor is anything but cheap, if the investors have to put up with building delays and shoddy workmanship. Investors should instead start looking for contractors who can deliver high-quality services and finish the project on time.

\section{Conclusion}

This article presents the idea that innovations are a significant factor in a construction company's pursuit of success, and they can provide many advantages to the company. Innovations have an impact on business and construction processes, the company's environment and all participants. In order to succeed, construction companies have to be innovative and responsive to innovation. They need to support creativity and innovativeness at work. Companies that are stuck in a rut and reject innovative thinking stand no chance in today's market.

In the article, an overview of the innovation activity in Slovenia is presented first. An examination of the results has shown weak innovation activity, which serves as a basis for the preparation of an integrated approach for the implementation of innovation in companies in construction industry. The approach consists of the basic factors and relevant elements from internal and external environment of the company. The basic factors from internal environment for a successful implementation are: timing, i.e. when does the construction company decides to implement innovation; the level to which the implementation of innovation needs implicit and explicit coordination; the choice of resources and type of professional resources, and the supervision of activities. As two elements resulting from an internal environment are the form of innovation and rising benefits. Elements that result from external environment and have the greatest influence on the success of innovations are participants, e.g. clients, investors, subcontractors, suppliers, and factors of innovation such as universities or research institutes. As an external element we have also presented several inhibitors of innovation. When implementing innovation into processes, we need to use a proper approach for its expanding. In the article, two non-technological approaches for expending innovations (partnering and supply chain management), suitable for Slovenian's construction industry, are presented. Properly applied approaches can significantly improve a company's effectiveness, especially between companies and projects.

By introducing or breaking down the individual elements of innovation, we have come to the conclusion that innovations do not pop out of thin air; on the contrary, all elements must be considered in order to achieve a successful implementation of innovation in the construction processes. This is the only way in which the construction industry will be able to leave the past behind and step into the future. 


\section{Literature and sources}

Blayse, A., Manley, K. (2004), “Key influences on construction innovation”, Construction Innovation, Vol.4 No.3, pp. 143-154.

Desphande, R., Farley, J.U., Webster, F. E. Jr. (2000), "Triad lessons: Generalizing results on high performance firms in five businessto-business markets", International Research in Marketing, Vol. 17 No.4, pp. 353-362.

Foust, D. (2008), Business Week 7. April: The best 50 Performers of 2008, McGraw-Hill Companies, New York.

Freeman, C. \& Perez, C. (1988), StructuralCricesofAdjustment: Business Cyclesand Investment Behaviour. Technical Change andEconomicTheory, London: Pinter Publisher.

Jimenez-Jimenez, D., Valle, R.S. \& HernandezEspellardo, M. (2008), “Fostering innovation: The role of market orientation and organizational learning”, European Journal of Innovation Management, Vol.11 No.3 pp. 389-412.

Jones, M., Saad, M. (2003), Managing innovation in construction, Thomas Telford, London.

Konda, I. (2005), Relationships on Marketing Channels in Business-to-business Marketing. Organization-Journal of Managmenet, Information Systems and Human Resources, Vol.38, No.5 pp 238-245
Myers, D. (2004), Construction Economics: A New Approach, Spoon Press, London.

Samad A. K. (2010), "Regional Construction Clustering in Action: Strategic Roadmapping and Action Planning Electronic source", available at: http://books.google.si/books/about/ Regionalni_gradbeni_grozdi_v_akciji. html?id=gOMVSQAACAAJ\&redir esc $=y$ (accessed 10 February 2013).

Slaughter, S. (1998), “Models of Construction Innovation", Journal of Construction Engineering and Management, Vol. No.May/June., pp.226-231.

SORS - Statistical office of the republic of Slovenia. "Innovation activity in manufacturing and selected services, Slovenia 2008-2010 - final data", available at: http://www.stat.si/novica_prikazi. aspx?id=4692 (accessed 10 February 2013).

Trontelj, Ž. (2007), The influence ofpublic-pr ivatepartnershipuponconstructionproce ss, diploma thesis, Universityof Ljubljana, FacultyofCivilandGeodeticEngineering, Ljubljana. (in Slovene)

Vazquez, R., Alvarez, I. L., Santos, M. L. (2002), "Market orientation and social services in private non-profit organisations", European Journal of Marketing, Vol.36 No.9/10, pp. 1022-1046. 